\begin{tabular}{|c|l|}
\hline Title & Municipal solid waste management in Tehran : Changes during the last 5 years \\
\hline Author(s) & Malmir, Tahereh; Tojo, Y asumasa \\
\hline Citation & $\begin{array}{l}\text { Waste management \& research, 34(5), 449-456 } \\
\text { https://doi.org/10.1177/0734242X 16632056 }\end{array}$ \\
\hline Issue Date & 2016-05 \\
\hline Doc URL & http://hdl.handle.net/2115/62267 \\
\hline Type & article (author version) \\
\hline File Information & Tahereh Malmir and Y asumasa Tojo.pdf \\
\hline
\end{tabular}

Instructions for use 


\title{
Municipal solid waste management in Tehran: Changes during the last 5 years
}

\section{Tahereh Malmir and Yasumasa Tojo}

\begin{abstract}
The situation of waste management in Tehran was a typical example of it in developing countries. The amount of municipal solid waste has been increasing and the city has depended on landfill for municipal solid waste management. However, in recent years, various measures have been taken by the city, such as collecting recyclables at the source and increasing the capacity of wasteprocessing facilities. As a result, significant changes in the waste stream are starting to occur. This study investigated the nature of, and reasons for, the marked changes in the waste stream from 2008 to 2012 by analysing the municipal solid waste statistics published by the Tehran Waste Management Organization in 2013 and survey data on the physical composition of the municipal solid waste. The following trends were identified: Although the generation of municipal solid waste increased by $10 \%$ during the 5-year period, the amount of waste directly disposed of to landfill halved and resource recovery almost doubled. An increase in the capacity of a waste-processing facility contributed significantly to these changes. The biodegradable fraction going to landfill was estimated by using the quantity and the composition of each input to the landfill. The estimated result in 2012 decreased to $49 \%$ of its value in 2008 .
\end{abstract}

\section{Keywords}

Waste management in developing countries, waste stream, waste composition, landfilling, resource recovery from waste, biodegradable fraction in landfilled waste

\section{Introduction}

Management of municipal solid waste (MSW) is a key issue in cities worldwide. The acceleration of MSW production and the complexity of its composition caused by population and economic growth and rapid urbanisation complicate the issue. Although there have been drastic improvements in MSW management in developed countries, the situation in developing countries still requires considerable attention. At present, many cities in developing countries rely on landfill or open dumping for their MSW disposal. However, many megacities are facing serious environmental threats posed by uncontrolled open dumping and are suffering from a decrease in landfill capacity (Aprilia et al., 2012; Hazra and Goel, 2009; Talyana et al., 2008). It is clear that the construction of additional new landfills in these megacities is difficult. Considering the trend of decreasing landfill capacity, measures to move away from the dependence on landfills are urgently required in megacities worldwide.

Because direct disposal of waste into landfills requires longterm management (Heyer et al., 2005), European Union (EU) countries have been shifting to the disposal of pretreated waste based on an EU directive on landfills (European Union Council Directive, 1999), and have been trying to reduce the biodegradable fraction that enters landfills. In this regard, the massive landfills of the megacities of developing countries may become a difficult legacy for future generations. Hence, reduction in the biodegradable fraction entering the landfill should be given special consideration.
The city of Tehran (the capital of the Islamic Republic of Iran), with a population of approximately 8 million in 2011 and an area of approximately $1301 \mathrm{~km}^{2}$, is located roughly in the centre of the country (Tehran Annual Report, 2014). Tehran has 22 municipal districts and 123 subdistricts, and the Tehran Waste Management Organization (TWMO) is responsible for their waste management. According to Abduli (1995), the city had two landfill sites (Abali and Kahrizak) in the past. Each site accepted almost half of the MSW generated from the city. Since the Abali site caused many serious environmental issues, it was closed to MSW in 1991. Subsequently, the Kahrizak Landfill was renamed the Arad Kouh landfill, and became the main site for MSW disposal generated from the city, but the landfill also generated environmental pollution (Abduli, 1995). Nevertheless, even in 2008, almost $87 \%$ of the waste generated from the city was disposed of into this landfill (Abduli, 2010). A compost plant with an intake capacity of 500 tday $^{-1}$ began operating in 1998 in the vicinity of the Arad Kouh Landfill. However, the contribution of this compost plant to waste treatment was only $5 \%$ of the total amount

Graduate School of Engineering, Hokkaido University, Sapporo, Japan

\section{Corresponding author:}

Tahereh Malmir, Graduate School of Engineering, Hokkaido University, N13W8, Kitaku, Sapporo 060-8628, Japan.

Email: malmirawdlms2-sw.eng.hokudai.ac.jp 


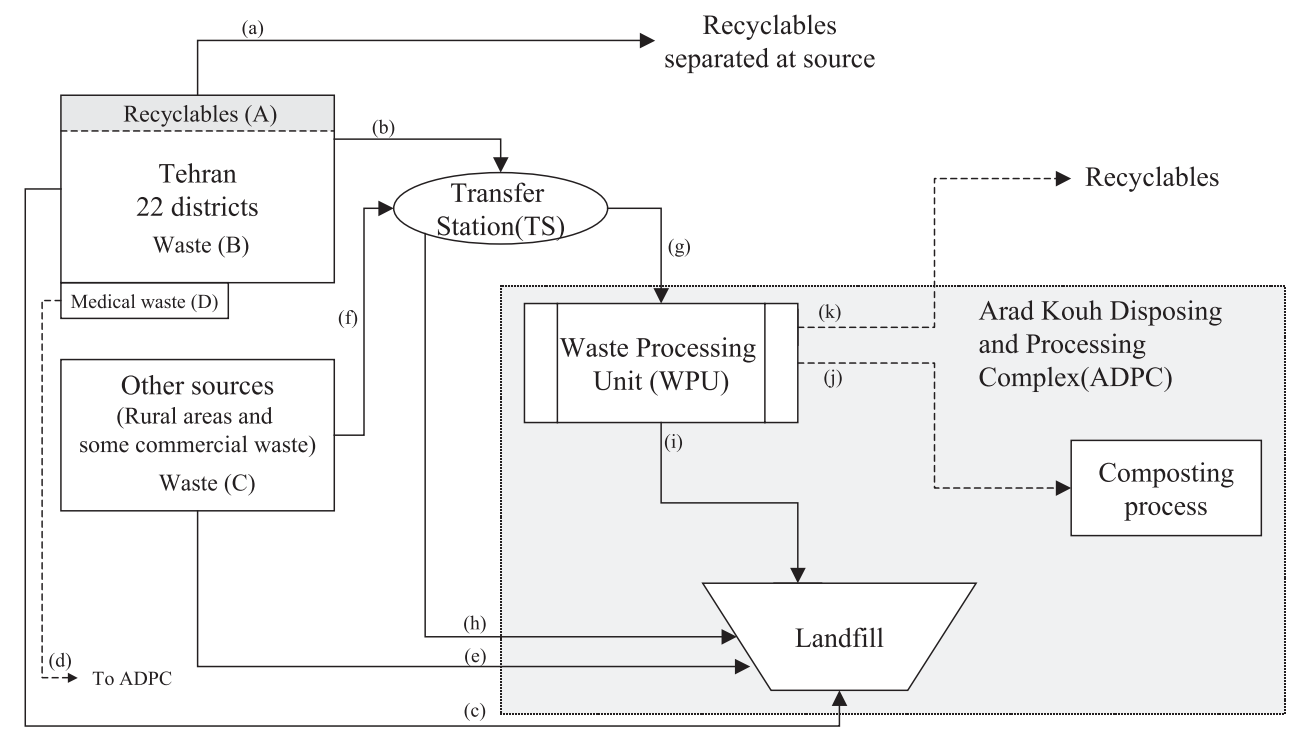

Figure 1. Waste flow in Tehran (letters (a)-(k) correspond to the explanations in the text).

of waste in 2008. Collection of recyclable materials has been performed by the city on a small scale, but accounted for only $5 \%$ of MSW in 2005, and the major item of collected waste was stale bread (Damghani et al., 2008).

In recent years, various measures have been taken by the municipality of Tehran. The city improved the collection of recyclable materials at their source; installed a waste processing unit (WPU) with four waste sorting lines (these sorting lines comprised mechanical and hand-sorting processes) in the vicinity of the Arad Kouh landfill in 2005 and expanded into 12 processing lines between 2008 and 2012; increased compost production by constructing new composting sites at the existing composting plant; and constructed a new landfill section, which is a sanitary landfill based on international standards, in the Arad Kouh landfill, commencing its operation in 2010. All these facilities, including WPU, composting sites and sanitary landfill, are collectively called the Arad Kouh Disposing and Processing Complex (ADPC).

In addition, various laws and regulations have been enacted in the past 10 years. According to Abduli et al. (2013: 532), 'The national SWM law was enacted as of 29 May 2004. Article 4 mentions that the capital and all cities with a population of over 1 million should have implemented a source separation program by 20 March 2012, as well as an increase in the volume of recyclables collected, thereby reducing the volume of MSW going to landfills. The deadline for other cities is 20 March 2014'. Owing to these various efforts, marked changes in the waste stream have occurred in Tehran, especially between 2008 to 2012. Here, we describe these changes and discuss the reasons behind them in the form of a country report.

\section{Methodology}

\section{Waste flow in Tehran}

Figure 1 shows the current waste flow in Tehran. According to the statistics of the TWMO, there are four sources of waste and recyclables: (A) recyclables generated in the 22 city districts; (B) MSW generated in these districts; (C) MSW generated from other sources (companies and rural areas); and (D) medical waste generated in these districts. Though both (A) and (B) are generated in 22 districts, their amount was recorded separately because their flows are different. If we follow the definition of waste, which is 'any substance or object which the holder discards or intends or is required to discard' (European Union, 2008), the sum of the amount of (A) and (B) can be regarded as the 'true waste' generated in these districts.

There are three pathways of waste/recyclables from these districts, as shown in Figure 1 (denoted as lowercase letters). The first is source separation of recyclables (a). Since 2005, various source separation schemes have been implemented. According to the TWMO, Heravi and Sabour (2012) and Heravi et al. (2013), the major collection methods of recyclable materials are drop-off centres, door-to-door collection using blue polyethylene bags, and collection by curbside containers. The collected recyclable waste materials comprise stale bread, plastics, paper and cardboard, metal, glass and so forth.

The second pathway of MSW from districts is routine collection (b) performed by the TWMO. A daily waste collection service is provided each night. Collection vehicles (mechanised compacting vehicles) collect the waste and transport it to transfer stations (TSs); there are 11 TSs. At these TSs, waste delivered by the collection vehicles is unloaded directly to the cargo bed of a semi-trailer (mostly open type trailer). Hence, the main duty of the TS is just to transfer MSW from the collection vehicles to semi-trailers in order to transport waste economically and efficiently, since the ADPC is located about $40 \mathrm{~km}$ away from the city centre.

The third pathway is direct disposal to the landfill (c). The types of waste that are directly disposed of into the landfill include sludge, soil and yard trimmings, generated mainly from public works. 
Medical waste is another source. This waste is directly transported to the ADPC (d) and is disposed of in a sanitary way at a designated location in the landfill. However, because the amount of this type of waste is insignificant, it is given little attention in this report.

MSW generated in rural areas and some commercial wastes (C) are also treated by the TWMO. Some of this waste is transported to the $11 \mathrm{TSs}$ (f), and the rest is sent directly to the landfill in the ADPC (e).

Most of the waste delivered to TSs is taken to the WPU located in the ADPC (g), but some of it is sent from the TSs directly to the landfill in the ADPC (h). The amount of (g) depends on the capacity of the WPU. When the WPU capacity is small, most of the waste received at the TS is transferred to the landfill by the flow of (h). But according to the gradual increase of the capacity of the WPU, the flow of $(\mathrm{g})$ increases and $(\mathrm{h})$ decreases.

At the WPU in the ADPC, the waste is separated into recyclable materials (k), a fine fraction composed of mainly biodegradable organic matter (j) and a coarse fraction (i) (called 'reject materials') which is mainly plastic and paper that do not suit recycling because of contamination. Currently, reject materials are sent to the landfill, but there are plans for it to be treated in an incinerator or energyrecovery facility in the future. Operation of the WPU is assigned to private contractors by the TWMO, and recyclable materials $(\mathrm{k})$ separated by these contractors are sold to recycling facilities, which are operated by both private companies and public institution. Materials separated as recyclables are cardboard, plastic, polyethylene terephthalate (PET), aluminium, etc. According to Heravi and Sabour (2012), recyclable materials, such as ferrous metal, cardboard and aluminium cans, are pressed and baled, then transferred to their recycling facilities. The fine fraction is sent to the composting facility located adjacent to the WPU and turned into compost.

There are four inflows to the landfill: direct disposal from districts (c), direct disposal from other sources (e), direct disposal via TSs (h) and reject materials from the WPU in the ADPC (i).

\section{Collection of data on waste generation}

The amount of waste at each location of the waste stream indicated in Figure 1 is measured by the TWMO using equipment such as weighbridges. All of these data are gathered by the TWMO and summarised as tables of statistics. The TWMO occasionally publishes reports based on these statistics to evaluate the status of waste management. We used its 2013 report (TWMO, 2013) in our analysis.

However, as a matter of course, there are involvements of scavengers and informal sectors for recycling of MSW in Tehran city, as well as other developing countries. Unfortunately, there was no statistical information about the activity of them, so no estimation could be done for the rate of their interference. Therefore, since the analysis of this study was based on the data collected by the TWMO (i.e. the data is derived from the amount officially measured/determined), activity of the informal sector is not included.

\section{Waste composition survey in 2008}

In 2008, the TWMO conducted a project to analyse waste composition. Waste was collected from three points in the waste stream: generation sources, TSs and the ADPC. Each waste sample obtained at these different points was analysed. A summary follows.

Generation sources. To collect samples from residential sources, the cooperation of more than 2500 household and nonhousehold generators in 22 districts was requested in discharging their waste into designated plastic bags of $60 \mathrm{~L}$ capacity. More than 10,000 plastic bags were distributed. In total, 1049 samples from household sources and 1310 samples from non-household sources were collected. Owing to the lack of cooperation by residents, a good recovery ratio could not be achieved.

Collections from TSs. Samples were taken directly from the waste collection vehicles (mechanised compacting vehicles) arriving at the TSs (at the end of flow (b) in Figure 1). Each night, one vehicle was selected randomly from among the vehicles. This selection was made for vehicles from all 123 municipal subdistricts. At TSs, these vehicles directly discharge the waste to the cargo bed of a semi-trailer. One $60 \mathrm{~L}$ sample was taken from the selected vehicle when the waste was discharged. This was done over 10 days.

Collections from the ADPC. Each night, one semi-trailer (with a capacity of approximately $60 \mathrm{t}$ ) metric tonne $(\mathrm{t})=1000 \mathrm{~kg}$ or $2204.6 \mathrm{lb}$ (instead of ton $=1016.05 \mathrm{~kg}$ or $2240 \mathrm{lb} \mathrm{UK}(907 \mathrm{~kg}$ or $2000 \mathrm{lb}$ US)) - please confirm units or re-calculate as necessary - please check throughout the article.]from each TS was selected after entering the ADPC (at the end of flow (g)) and three samples were taken from the front, middle and end sections of the cargo bed of the open type trailer. The volume of each sample was approximately $80 \mathrm{~L}$. Because there were $11 \mathrm{TSs}$ and 33 samples were collected each night, 330 samples were obtained during 10 days.

All samples from each location were weighed. Then the composition was analysed. The components were classified into 20 categories: organic waste, stale bread, paper, cardboard, paper packaging, wood, textile, leather, rubber, plastic, PET, synthetic fibre, foam, glass, talc, soil, ferrous metals, non-ferrous metals, special waste and other. The materials of each category were separated and placed in baskets, which were weighed. The results of this project were published by the TWMO (2013). We use these data in the present article.

\section{Composition of reject materials from WPU at the ADPC}

As mentioned previously, at the WPU, recyclable resources are collected by sorting (k), and materials that are not separated as resources become reject (i). The separation of ferrous metal is done by a magnetic separator and other recyclables (such as cardboard, PET, aluminium and glass) are separated by hand sorting. The labourers pick them up visually so that these 


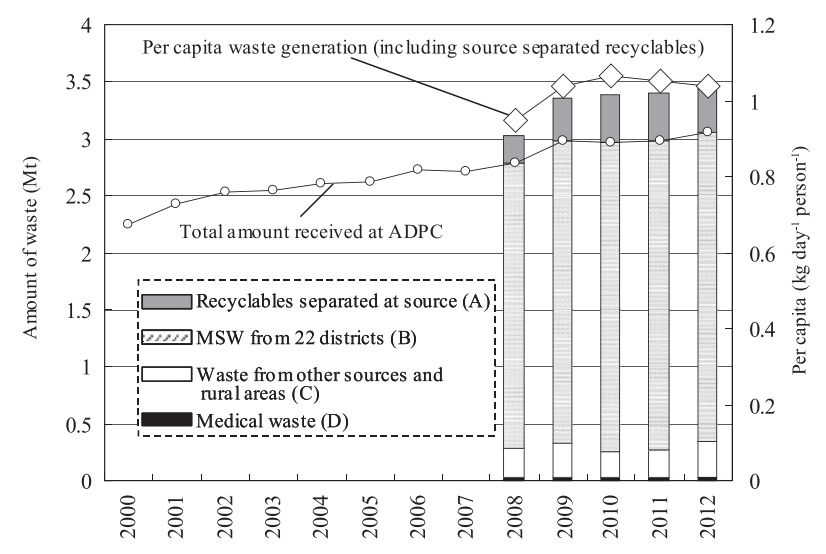

Figure 2. Waste generation from 2000-2012.

The letters (A)-(D) in the explanatory notes indicate each waste generation point in Figure 1 and $1 \mathrm{~m}$ t refers to $1 \mathrm{Tg}$ ).

materials are limited to what are relatively large in size and less contaminated. Hence, the composition of the reject is determined depending on the separation efficiency. Because contaminated plastics and paper do not suit recycling, they are not picked up and become rejects.

The composition of the reject material is periodically surveyed at the WPU in the ADPC. The methodology is as follows. Commingled reject samples are collected every $30 \mathrm{~min}$ from a conveyor belt, and the weights of each component (plastic, glass, metal, etc.) are measured. Then the percentage that each component contributes to the total weight is determined. In this article, the results of 2008 are cited for comparison with the results obtained from the physical composition survey conducted at the three points in 2008 (as described in the section 'Waste composition survey in 2008').

\section{Results and discussion}

\section{Trend in waste generation in Tehran}

Figure 2 shows the trend in waste generation in Tehran. Because the data aggregation method has changed several times during last two decades and data on source separation before 2008 were unavailable, the total amount of waste accepted at the ADPC is indicated from 2000 to 2012 by a line in the figure.

The amount of recyclable materials separated at source ((A) in Figure 1), and the amount of waste accepted at the ADPC distinguished by each source ((B), (C) and (D)) were obtained from 2008 to 2012 and are indicated separately by bar charts. The total amount of waste received by the ADPC gradually increased from about $2.2 \mathrm{mt}$ in 2000 to $3.1 \mathrm{mt}$ in 2012 . The mean annual rate of increase was approximately $62,000 \mathrm{ty}^{-1}$, based on linear regression analyses. From 2008 to 2012, the amount of waste increased by approximately $10 \%$.

From the bar chart, it can be seen that the waste collected from the 22 districts ((B) in Figure 1) accounts for approximately $80 \%$ of the total waste $((A)+(B)+(C)+(D))$. The waste from other sources and rural areas (C), medical waste (D) and waste separated at source (A) made up almost $8 \%, 1 \%$ and $11 \%$, respectively. The amount of $((\mathrm{A})+(\mathrm{B}))$ that is generated in the 22 districts was $2.7 \mathrm{mt}$ in 2008 and $3.1 \mathrm{mt}$ in 2012. This amount can be regarded as the 'true MSW' generated from Tehran when considering the definition of waste described the section 'Waste flow in Tehran'. The share of medical waste (D) was low. Waste from other sources (C) fluctuated randomly because of the variation in the quantity of waste from adjacent cities.

Recyclables separated at source (A) sharply increased from 2008 to 2009. But it slightly decreased from 2010. Based on the TWMO statistics, recyclables separated at source were stale bread $(21 \%)$, plastic $(16 \%)$, paper and cardboard (34\%), metal (14\%), glass (4\%), PET (6\%) and others $(5 \%)$ in 2011. The decrease from 2010 could be attributed to the Iranian-targeted subsidy plan, which was enacted in 2010. Based on this law, as an instance, the price of bread increased sharply and led to a more suitable use of bread by households. Therefore, people became accustomed to buy bread more fitting to their needs and consequently the amount of stale bread decreased considerably.

Per capita generation was calculated by summing the recyclables separated at source (A), the MSW from the 22 districts (B) and dividing the result by the population of the relevant year as indicated in:

$$
\text { Per capita generation }=\frac{\text { Recyclables }_{\text {separated at source (A) }}}{\text { Population of the relevant year }}
$$

The population of Tehran was approximately 8 million during these 5 years. Based on this calculation, per capita generation was increased from $0.92 \mathrm{~kg} \mathrm{day}^{-1}$ person $^{-1}$ in 2008 (since $(A)+(B)=2.7 \mathrm{mt}$ ) and increased to $1.1 \mathrm{~kg} \mathrm{day}^{-1}$ person $^{-1}$ in 2012 $((\mathrm{A})+(\mathrm{B})=3.1 \mathrm{mt})$. If this amount is calculated excluding recyclables separated at source, per capita waste generation decreased to approximately $0.86-0.92 \mathrm{~kg} \mathrm{day}^{-1}$ person $^{-1}$ during the 5-year period.

\section{Changes in waste flow}

Figure 3 shows changes in the destination of waste from 2008 to 2012 and the output from the WPU at the ADPC.

As can be seen in the figure, there are three destinations for generated waste in Tehran: Direct disposal into the landfill at the ADPC $((\mathrm{c})+(\mathrm{e})+(\mathrm{h})$ in the figure), waste processed by the WPU at the ADPC (g) and recyclables separated at source (a). The output from the WPU after sorting included reject material (i), the fine fraction sent for composting (j), and resources recovered at the WPU (k).

A distinctive change between 2008 and 2012 was the considerable decrease in direct disposal to the landfill $((\mathrm{c})+(\mathrm{e})+(\mathrm{h}))$ and a significant increase of waste processed at the WPU (g). The reason for this increase was the marked increase in the capacity of the WPU initiated in November 2008. This change was motivated by the strategy of the TWMO management team toward 'zero landfill' (e.g. 16 April 2011, in Tabnak Newspaper). 


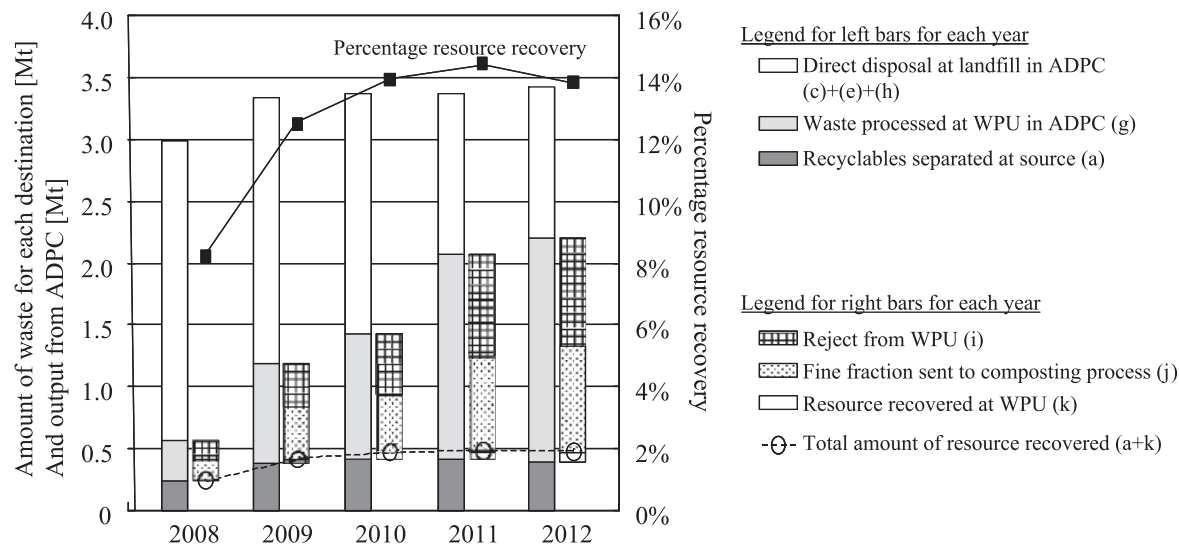

Figure 3. Changes in the destination of generated waste from 2008 to 2012 and output from the waste processing unit in the ADPC. Left bars for each year indicate the destination of the waste, and the right bars indicate output from the WPU in the ADPC after treatment.

The letters $(a)-(k)$ in the explanatory notes denote each path related to the destination and outputs in Figure 1.

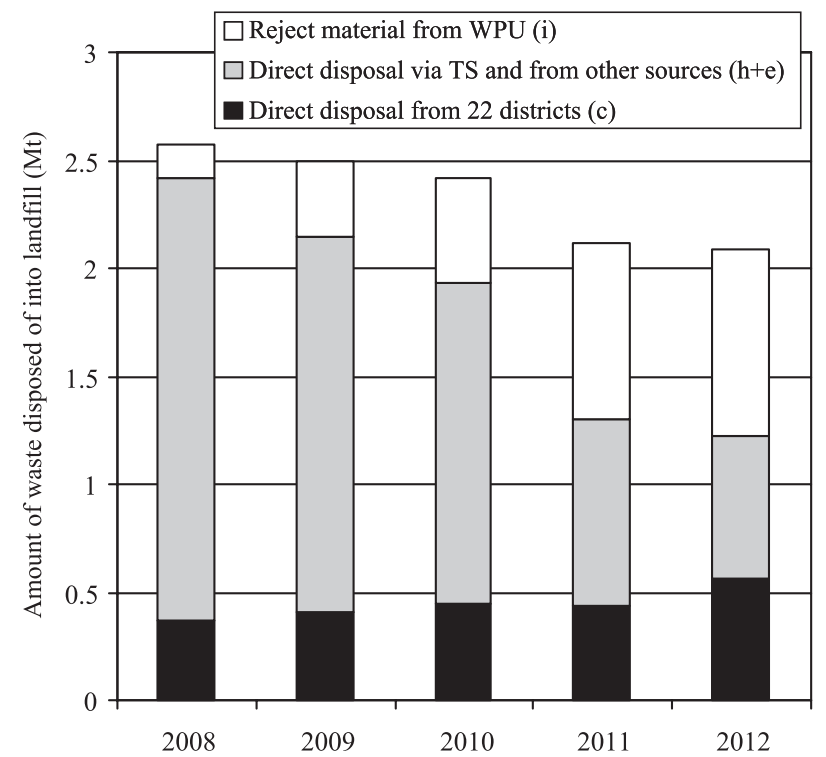

Figure 4. Decrease in the amount of waste disposed of into landfill from 2008 to 2012.

Letters in the explanatory notes denote each path to the landfill shown in Figure 1.

The WPU recovered significantly more resources over time. Though (k) is still small compared with others and it is hard to see in Figure 3, it increased almost seven-fold. Based on the TWMO performance report (TWMO 2012, TWMO 2013), about one-third of recyclable material is cardboard. Plastic, PET and aluminium are the other main components, respectively. The amount of fine fraction sent to the composting facility (j) also increased drastically and consequently more than one-quarter of the total waste in Tehran was treated for compost production in 2012. Since the generation of materials rejected from the sorting process is inevitable, the amount of 'reject' from the WPU (i) also increased. But this increase is a natural consequence of the increase in the capacity of the WPU.

To confirm how resource recovery in the city has improved, the percentage resource recovery was calculated (black squares in Figure 3). The percentage was calculated from the sum of recyclables separated at the source, the resources recovered at the WPU, and then dividing the result by the total amount of waste generated in each year (excluding medical waste) by using:

$$
\begin{aligned}
& \text { Recyclables } \\
& \begin{array}{l}
\text { Percentage } \\
\text { resource recovery }
\end{array}=\frac{+ \text { Recyclables }_{\text {recovered at WPU }(k)}}{\text { Total waste excluding }} \\
& \text { medical waste }(\mathrm{A}+\mathrm{B}+\mathrm{C})
\end{aligned}
$$

For instance, in 2008, ((a)+(k)) was $0.25 \mathrm{mt}$ and $((\mathrm{A})+(\mathrm{B})+(\mathrm{C}))$ was almost $3.0 \mathrm{mt}$, thus the percentage of resource recovery can be calculated as $8 \%$. This percentage increased to $14 \%$ in 2012 . This can be attributed to a strengthening of the source separation programme and the increased capacity of the WPU.

The amount of waste that ultimately entered the landfill is shown in Figure 4.

Three types of waste are turned to landfill at the ADPC. The total amount of landfilled waste decreased from $2.6 \mathrm{mt}$ to $2.1 \mathrm{mt}$ in 2012. However, changes in the types of waste entering landfill are more drastic. Direct disposal via TSs or from other sources ((h) $+(\mathrm{e}))$ accounted for about $80 \%$ of the total landfilled waste in 2008. This means that most of the MSW generated in Tehran city simply passed through the TSs before being directly disposed of into the landfill. As mentioned in the 'Waste flow in Tehran', this is owing to less capacity of the WPU. However, by 2012, the amount of waste $((\mathrm{h})+(\mathrm{e}))$ had dropped dramatically to about $0.7 \mathrm{mt}$. Consequently, the predominant type of waste shifted to reject materials (i). This implies that the quality of waste entering the landfill changed significantly because organic matter in reject might be less than MSW itself.

The changes in waste flow that occurred in Tehran during 2008-2012 are indicated in Figure 5. The upper number in each box shows the amount of waste in 2008, and the lower number shows that in 2012.

The numbers enclosed by a circle in the figure indicate the following: (1) the amount of recyclables separated at source 


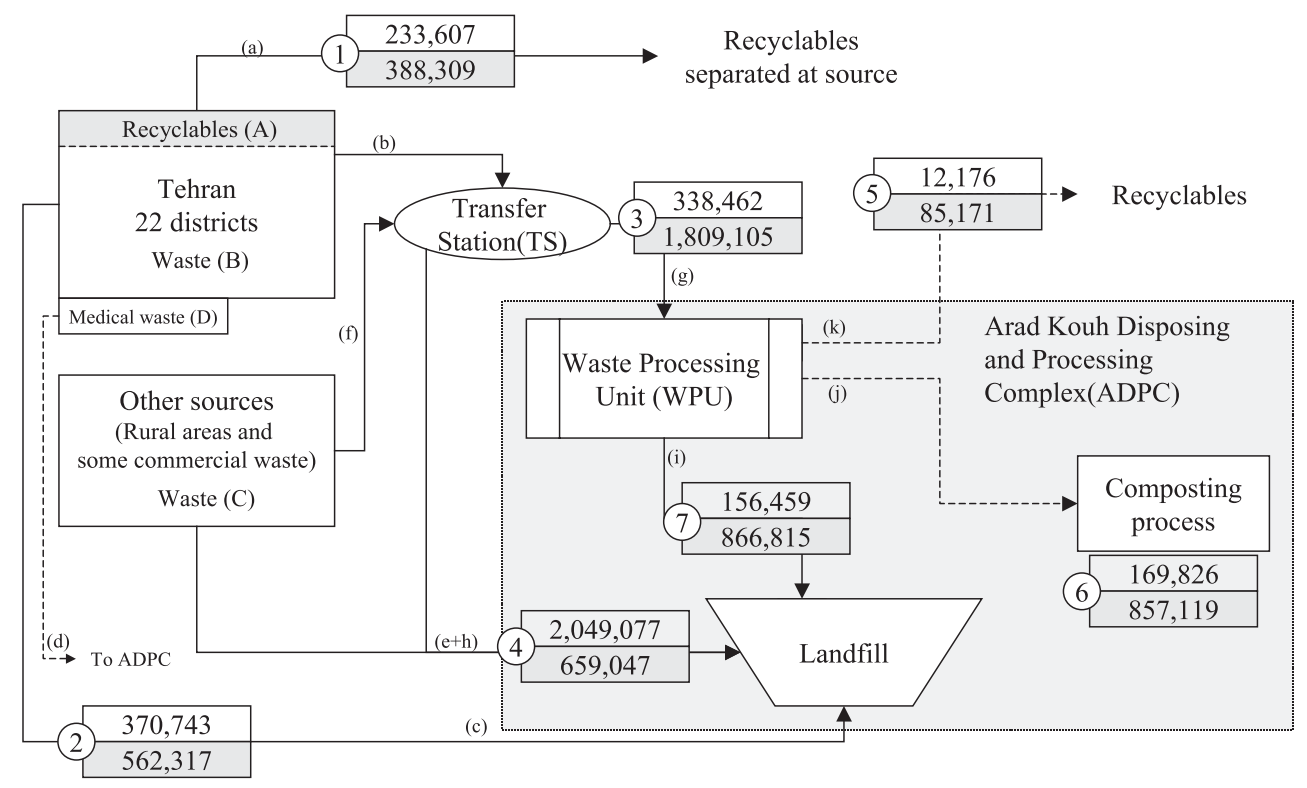

Figure 5. Changes in waste flow (in metric tonnes) between 2008 (upper section of the figure) and 2012 (lower section of the figure). Here, numbers are directly cited from TWMO (2013) statistics.

Table 1. Waste composition at different locations of the waste flow in Tehran in 2008 and composition of reject materials from the WPU in 2008.

\begin{tabular}{lllllllllll}
\hline Component & $\begin{array}{l}\text { Organic } \\
\text { waste }\end{array}$ & $\begin{array}{l}\text { Stale } \\
\text { bread }\end{array}$ & Paper & Wood & $\begin{array}{l}\text { Textile, leather, } \\
\text { rubber }\end{array}$ & Plastics & $\begin{array}{l}\text { Glass, } \\
\text { stone, soil }\end{array}$ & Metal & Others & Total \\
\hline At source & $61.2 \%$ & $5.5 \%$ & $13.5 \%$ & $0.8 \%$ & $1.9 \%$ & $8.3 \%$ & $3.4 \%$ & $3.0 \%$ & $2.5 \%$ & $100 \%$ \\
At TS & $67.4 \%$ & $0.9 \%$ & $9.4 \%$ & $0.2 \%$ & $3.5 \%$ & $9.6 \%$ & $3.6 \%$ & $1.6 \%$ & $3.8 \%$ & $100 \%$ \\
At ADPC & $72.2 \%$ & $1.0 \%$ & $8.9 \%$ & $0.3 \%$ & $3.7 \%$ & $5.9 \%$ & $3.3 \%$ & $1.2 \%$ & $3.4 \%$ & $100 \%$ \\
Reject material & $29.2 \%$ & $0.5 \%$ & $15.5 \%$ & $2.0 \%$ & $7.6 \%$ & $26.9 \%$ & $9.0 \%$ & $1.3 \%$ & $8.0 \%$ & $100 \%$ \\
\hline
\end{tabular}

TS: transfer station (survey was performed at the end of flow (b) in Figure 1); ADPC: Arad Kouh Disposing and Processing Complex (survey was performed at the end of flow (g) in Figure 1).

increased 1.66-fold between 2008 and 2012; (2) direct disposal from the 22 districts increased 1.5-fold, but this change was caused by several public works' projects; (3) the amount of waste sent to the WPU via TSs and processed at the WPU increased more than 5-fold; (4) direct disposal via TSs and other sources decreased to $32 \%$, and total direct disposal (direct disposal via TS/other sources, plus that from the 22 districts) halved; (5) resources recovered at the WPU increased about 7-fold; (6) the organic fraction treated at the compost facility increased 5-fold; and (7) owing to the increase in waste accepted at the WPU, reject materials sent to the landfill increased 5.5-fold.

These data demonstrate clear changes in waste flow. Therefore, it can be seen that Tehran's initiatives to improve their waste management has been very effective.

\section{Results of waste composition survey}

Table 1 shows the composition of waste as determined by the survey conducted in 2008. The composition at the source of generation was surveyed separately for households and non-households, but Table 1 combines the results. Table 1 also combines results for similar items (e.g. paper, cardboard, and paper packaging were unified under 'paper').
The largest component of waste was organic waste, which accounted for almost $60 \%-70 \%$ of the waste at each location. The percentage of stale bread decreased at the TSs and ADPC. The bread was probably mixed with other organic waste during transportation. The sum of other organic components (paper, wood, textile, leather and rubber) accounted for almost $13 \%$ $16 \%$ and the sum of the components of the inorganic fraction (glass, stone, soil, metal and others) accounted for $8 \%-9 \%$ at each location. With regard to the composition of the rejected material, the percentage of organic waste decreased to less than one-half when compared with what observed at other three locations. This was achieved by the sorting process at the WPU, but this figure should be improved further. Other major components of the rejected materials were plastics $(27 \%)$, paper $(16 \%)$, textiles, leather and rubber (8\%). The inorganic fraction (glass, stone, soil, metal and others) accounted for almost $18 \%$.

\section{Estimation of biodegradable fraction disposed of into landfill}

Considering that the waste stream changed significantly during the 5 years studied, and the quality and quantity of waste disposed of into landfill also changed, we estimated the change in 


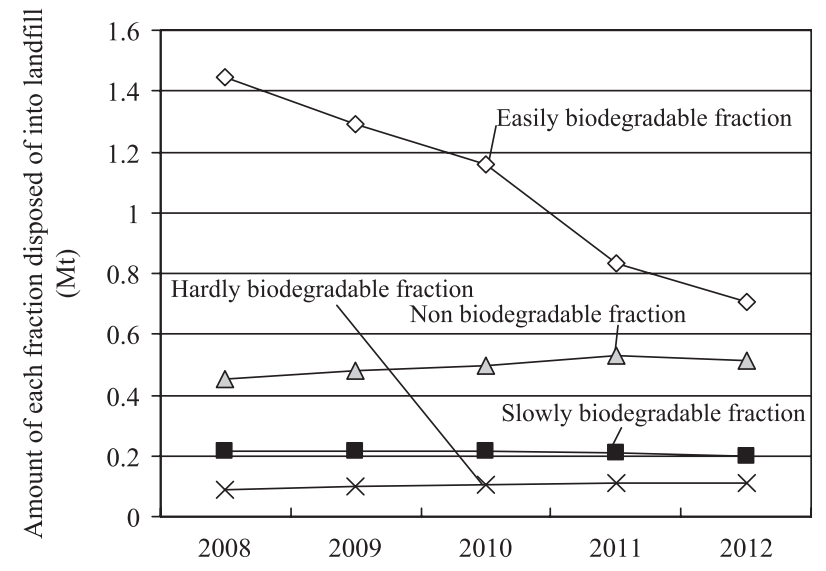

Figure 6. Changes in the amounts of the biodegradable fractions disposed of into landfill between 2008 and 2012.

the amount of biodegradable matter disposed of into landfills. This figure is important because the amount of biodegradable organic matter is an important target in the EU directive on landfills. As previously stated, there are three routes for waste to end up as landfill (i.e. (i), (h)+(e), and (c)). Therefore, if we can determine the quantity and quality of waste for each route, we can estimate the amount of biodegradable material sent to the landfill. Among the three routes to the landfill, direct disposal from 22 districts (c) was ignored because, as mentioned above, it consists of mainly sludge, soil and yard trimmings generated from public works. Based on the composition survey in 2008, waste transferred to the ADPC via the TS is known. The composition data of the material rejected from the WPU also exists. Thus, the biodegradable fraction of the waste taking these two routes can be determined based on the composition data. Easily biodegradable components are organic waste and stale bread. Paper can be regarded as slowly biodegradable material. Wood, textiles and leather are considered to be hardly biodegradable. The remaining components, such as plastics and metals, are regarded as nonbiodegradable. To calculate each amount of biodegradable matter, the fraction of each component was multiplied by the amount of waste in each path in each year. For this estimation, waste composition data for each year should be used, but they were unavailable. Hence, the assumptions of the calculation were as follows: The composition of waste transferred to the ADPC via the TSs and the composition of the reject materials from the WPU did not change significantly during the 5 years; and as the amount of waste directly sent to the landfill from other sources was small compared with the waste sent directly via the TS, their composition assumed to be the same.

Figure 6 shows the results, categorised into classes of biodegradability: Easily biodegradable, slowly biodegradable, hardly biodegradable and non-biodegradable.

Because the estimations are based on the results of the physical composition survey, they can be considered rough estimations. In 2008, the easily biodegradable fraction was large (approximately $1.4 \mathrm{mt}$ ) because most of the MSW that contained organic waste, about $70 \%$, was directly disposed of via the TSs. However, the easily biodegradable fraction gradually decreased each year owing to the separation of the organic fraction by the WPU and its processing for compost production. This fraction was reduced to $0.7 \mathrm{~m} \mathrm{t}$ in 2012 . If the amount of this fraction in 2008 is taken to be $100 \%$, it decreased to $49 \%$ in 2012, whereas the non-biodegradable fraction increased slightly. No significant change was identified in the other two fractions. EU Member States are obligated to reduce the amount of biodegradable waste to be landfilled to $35 \%$ of its level in 1995 by 2016 (for some countries, by 2020). The reduction in the landfilled fraction of biodegradable waste in Tehran did not reach this target. However, the reduction that was achieved demonstrates that reductions in both waste and organic fractions that go to landfills are possible, even in developing countries.

As indicated so far, the strategy taken by the TWMO for waste management can be regarded as successful, especially for a reduction of the final disposal amount to landfill and it surely leads to the reduction of future emissions from landfill (such as emission of greenhouse gas). However, these reductions were achieved by significantly relying on composting.

When considering utilisation of compost created from MSW for the agriculture purpose, its characteristics, especially concentration of hazardous substance, must be taken into account. Up to now, several researchers investigated and reported the concentration of these substances in compost produced in Tehran (Farzadkia et al., 2009; Hosseinzadeh and Safari, 2006; Tarebari et al., 2010). They assessed its quality by comparing their results with Iranian and international standards on compost. Their evaluation results are: overall the quality of compost satisfies these standards; however, some heavy metals, such as lead and copper, tend to exceed the standards. Based on these results, careful monitoring on the parameters in compost must be continued.

\section{Conclusion}

In this article, changes to the waste management situation in Tehran from 2008-2012 were discussed, based on the statistics of the TWMO, given that waste flow has drastically changed in the past few years owing to various measures having been taken. Our analyses revealed the following trends.

- The total amount of waste generated in Tehran gradually increased between 2000 and 2012. The mean annual rate of increase was approximately $62,000 \mathrm{ty}^{-1}$. The total amount of waste increased by 10\% during 2008-2012.

- The amount of recyclable materials collected at source increased because of the effects of various source separation schemes that were implemented from 2005. The amount increased 1.66-fold from 2008 to 2012.

- The amount of waste processed at the WPU increased more than five-fold. This was caused by an increase in the capacity of the WPU after 2008. 
- Direct disposal to landfills via TSs in 2012 decreased to $32 \%$ of the amount in 2008. Total direct disposal (the sum of direct disposal via TSs and other sources and direct disposal from the 22 districts) halved.

- Resources recovered at the WPU increased seven-fold. Thus, the total resource recovery increased from $8 \%$ to $14 \%$.

- As a result of the reduction in direct disposal, the easily biodegradable fraction heading for the landfill in 2012 decreased to $49 \%$ compared with 2008 .

All of these achievements were realised based on a strategy of 'zero landfill' promoted by the TWMO and show that a reduction in both the waste and biodegradable fraction going to landfills is possible even in developing countries.

\section{Acknowledgements}

The authors would like to acknowledge the TWMO's staffs for their kind cooperation on data.

\section{Declaration of conflicting interests}

The authors declared no potential conflicts of interest with respect to the research, authorship, and/or publication of this article.

\section{Funding}

This research received no specific grant from any funding agency in the public, commercial, or not-for-profit sectors.

\section{References}

Abduli MA (1995) Solid waste management in Tehran. Waste Management \& Research 13: 519-531.

Abduli MA and Azimi E (2010) Municipal waste reduction potential and related strategies in Tehran. International Journal of Environmental Research 4: 901-912.

Abduli MA, Tavakolli H and Azari A (2013) Alternatives for solid waste management in Isfahan, Iran: A case study. Waste Management \& Research 31: 532-537.

Aprilia A, Tezuka T and Spaargaren G (2012) Household solid waste management in Jakarta, Indonesia: A socio-economic evaluation. In: Dr. Rebellon LFM (ed.) Waste Management-An Integrated Vision. DOI: 10.5772/51464. Available at: http://www.intechopen.com/books/ waste-management-an-integrated-vision/household-solid-wastemanagement-in-jakarta-indonesia-a-socio-economic-evaluation

Damghani AM, Savarypour G, Zand E, et al. (2008) Municipal solid waste management in Tehran: Current practices, opportunities and challenges. Waste Management 28: 929-934.
European Union Council Directive (1999) 1999/31/EC of 26 April 1999 on the landfill of waste. Available at: http://eur-lex.europa.eu/legal-content/ EN/TXT/?uri=CELEX:31999L0031 (accessed 1 May 2015).

European Union (2008) Directive 2008/98/EC of the European Parliament and the Council of 19 November 2008 on Waste and Repealing Certain Directives. Official Journal of the European Union, 22/11/2008.

Farzadkia M, Salehi S, Ameri A, et al. (2009) Qualitative survey and the comparison of produced compost in Khomein and Tehran compost plants. Iranian Journal of Health and Environment, Iranian Association of Environmental Health 3: 160-169.

Hazra T and Goel S (2009) Solid waste management in Kolkata, India: Practices and challenges. Waste Management 29: 470-478.

Heravi HM and Sabour MR (2012) Waste source separation management for urban mining: a change strategy to improve quality. International Journal of Computational Engineering Research 2: 1516-1520.

Heravi HM, Kannan N, Abdullah AM, et al. (2013) Evaluating sustainable waste management (household waste) in Tehran, Iran. Australian Journal of Basic and Applied Science 7: 207-215.

Heyer KU, Hupe K and Stegmann R (2005) Landfill aftercare-scope for action, duration, cost and quantitative criteria for completion. In: Proceedings of Sardinia tenth international waste management and landfill symposium, S. Margherita di Pula, Cagliari, Italy, 3-7 October, CD-ROM.

Hosseinzadeh $\mathrm{H}$ and Safari E (2006) Analyzing the quality of compost made of MSW from the points of metals compare to the standards of other countries. In: First conference of environmental engineering, University of Tehran, Tehran, Iran. Available at: http://www.civilica.com/PaperCEE01-CEE01_382.html (accessed 1 October 2015).

Tabnak (2011) Goodbye to a traditional way of landfilling in Kahrizak after 45 years. Tabnak Professional News 16 April 2011. Available at: http://www. tabnak.ir/fa/print/158911 (accessed 10 June 2015).

Talyana V, Dahiyaa RP and Sreekrishnanb TR (2008) State of municipal solid waste management in Delhi, the capital of India. Waste Management 28: 1276-1287.

Tarebari H, Akhavan Limoudehi F and Jafargholi A (2010) The contamination of produced compost from MSW and its destructive effects on human. In: The $4^{\text {th }}$ conference and exhibition on environmental engineering, University of Tehran, Tehran, Iran. Available at: http://www.civilica. com/Paper-CEE04-CEE04_329.html (accessed 2 October 2015).

Tehran Annual Report (2014) Tehran Governor, Department of Planning and Employment, Bureau of Statistics, published in 2014. Available at: http:// salnameh.sci.org.ir (accessed 2 June 2015).

Tehran Waste Management Organization (2012) The summary of annual performance report. Urban Service Department, Deputy of Urban Planning and Development. Available at: http://pasmand.tehran.ir/ Portals/0/Document/misc/91.pdf (accessed 10 October 2015).

Tehran Waste Management Organization (2013a) Evaluation of the statistics of waste production in Tehran city from 2008 to 2012. Urban Service Department, Deputy of Urban Planning and Development.

Tehran Waste Management Organization (2013b) The summary of annual performance report. Urban Service Department, Deputy of Urban Planning and Development. Available at: https://pasmand.tehran.ir/ Portals/0/Document/misc/92.pdf (accessed 10 October 2015). 